\title{
PREVALENCE OF VISUAL DISORDERS IN DEAF CHILDREN IN BENIN CITY
}

\author{
$\mathrm{BY}$ \\ OSAIYUWU*, A. B. AND EBEIGBE, J. A. \\ DEPT. OF OPTOMETRY, FACULTY OF LIFE SCIENCES, \\ UNIVERSITY OF BENIN, BENIN CITY, NIGERIA. \\ EMAIL: bosalyuwu@yahoo.com \\ *Corresponding author
}

\begin{abstract}
7 he most developed and most important of the special senses of the body is the sense of sight and hearing, both of which are predisposed to gradual impairment in the absence of the other. It has been shown that the occurrence of either visual impairment and deafness or hearing loss existing independently or co-existing have potential complications in the physical wellbeing of an individual child. Of the 86 students examined in this research, 34(39.53\%) were males while 52(60.47\%) were females. However, 63(73.26\%) subjects of the total population studied had visual disorders. The Pearson Correlation coefficient result of -0.77 showed a negative association in the distribution between age and visual disorders. It is thus advocated that prompt attention and treatment be paid to visual abnormalities in the hearing impaired child at an earlyage.
\end{abstract}

KEYWORDS Hearing impairment, visual disorders, cataract, ocular deviations, childhood diseases.

\section{INTRODUCTION}

Childhood impairment is a major problem throughout the world and results in a substantial life long burden of disability varying from visual impairment, mental impairment and most specifically deaf or hearing loss. In every child as well as in adults, much of knowledge is obtained through the senses of sight and hearing. When one of these is seriously impaired, the other is used to compensate. As the degree of impairment increases, the role of the remaining sense becomes progressively more significant. Thus, the deaf child may compensate by making greater use of the eyes and thus even a mild refractive error may reduce visual efficiency of the child. There are no conditions of disability which so frequently give rise to disorders of the eye, as deafness does .

Studies have shown that a deaf child is at greater risk of vision problems than a child who is not deaf and that comparative examination should be performed at identification of deafness ${ }^{2,3}$. The high rates of ocular pathology from the above studies have been attributed to important elements of the eye and ear (example retina and cochlea) maturing during the same embryological stage, from the same embryological layer which may be susceptible to genetic or environmental factors such as hypoxia, toxic agents, viruses, meningitis, and other conditions which may affect both eye and the ear ${ }^{4,5}$.

Rogers ${ }^{4}$ observed that the prevalence of ocular abnormalities generally increased with the severity of the hearing loss, of importance was the high prevalence of rubella-consistent abnormalities in the hearing impaired and deaf school aged children population. Roizen and Mets ${ }^{6}$ also observed that rubella syndrome may be responsible for a major portion of high refractive errors and ocular pathological changes in hearing impaired children.

There are two major causes of visual disorders in the hearing impaired: hereditary and environmental. Anomalies may be caused by defects in a specific chromosome or in a specific gene. Environmental causes could result from infections, malnutrition, drugs, chemical and physical factors like insufficient or excessive supply of oxygen, radiation and others ${ }^{5}$.

\section{RESEARCH METHODOLOGY}

A total number of eighty six (86) hearing impaired children between the ages of 6-16 years were examined in this study and they were recruited from the school for the deaf and dumb in Benin City. Children that were not willing to participate in the study were excluded. The teachers rendered great assistance in terms of interpreting commands to the students and also conveying the patients' responses to the examiner.

A form was created for each child where details as regards name, sex and age of the child and onset and duration of the deaf condition were recorded. Information was derived from either parent/guardian of such child. The other section of the form contained the ocular examinations carried out which include the visual acuity test, external examination, cover test, ophthalmoscopy and 
retinoscopy.

The Snellen chart was used in the determination of the visual acuity of each patient while the illiterate E chart was used for patients who could not read letters. The V.A measurement was done at distance. Ophthalmoscopy was carried out on all the patients to determine their ocular health status and in $30(34.88 \%)$ patients seen with miotic pupils; dilation was achieved by instillation of $1 \%$ tropicamide before direct ophthalmoscopy was carried out on them. The type of retinoscopy carried out on all the patients was static retinoscopy and cycloplegic refraction was carried out on those patients who were 6-10 years of age. Both the ophthalmoscopy and retinoscopy were done in dim illumination whereas the V.A test was done under bright illumination.

\section{RESULTS}

Of the 86 students examined 34 (39.53\%) were males while $52(60.47 \%)$ were females, however, $63(73.26 \%)$ subjects were observed to have visual disorders. Of this population with visual disorders $42(66.67 \%)$ were females and $21(33.33 \%)$ were males. The mean age of the females was $4.90 \pm 1.8 y$ yrs and that of the males was $9.90 \pm 2.6 y r s$.

Table 1 shows the distribution of visual disorders in the entire population studied. The age range of these subjects was between 6 to 16 years, most of whom (63 subjects/73.26\% of the total students studied) had visual disorders such as cataract, lid abnormalities, ocular deviation, pupil abnormalities, arcus juvenelis with other associating problems. All of the 63(73.26\%) subjects were observed to have refractive errors, while $23(26.74 \%$ ) subjects were not seen to have refractive errors nor visual disorders, the sex distribution of refractive error is as shown in table 2 and from the table, it is seen that female subjects had higher prevalence in the three refractive errors seen. From table 1, a higher percentage of females were affected than males except in arcus juvenelis affecting only the male population.

In the female population, as shown in table 3 , it was observed that there was a higher prevalence of visual disorders in subjects aged 6 and 8 years, while the males had a higher frequency of visual disorders at 10 years of age. Table 4 below shows the distribution of sex and ages of subjects without visual disorders. The Pearson correlation coefficient result of -0.77 revealed no significant difference $(\mathrm{P}<0.05)$ in the distribution of visual disorders with age or sex of subjects involved.

The external examination showed that a greater percentage of subjects with either optic nerve palsy or a neurological disorder accounted for $62.50 \%$ of subjects with pupillary disorders, many of whom had subconjunctival inflammation, eyelid coloboma, cataract and strabismus. In a gross inspection of the appearance of these subjects it was recorded that $23.80 \%$ of them had mental disorders, craniofacial disorders such as endophthalmus, enlarged frontal/occipital lobes giving rise to subjects with big heads, lumps behind and in front of their ears, rashes on their skin, as well as disfiguring or abnormal appearance of the face and skin.

These findings were consistent with past studies confirming the existence of diseases such as congenital rubella syndrome, Warrensburg syndrome and Sticker syndrome and in pregnant mothers ${ }^{7}$. The ophthalmoscopic findings revealed subjects with tigoid fundus $(3.17 \%)$, some were pale and transluscent $(23.82 \%)$ others were hazy $(28.57 \%)$ and a higher percentage had scattered areas of depigmentation $(34.92 \%)$ and patches of retinal pigment epithelium $(9.52 \%)$, possible explanation for this may be the existence of Usher's syndrome.

\section{DISCUSSION}

The prevalence of visual disorders among the deaf children in this study was found to be $73.26 \%$. The breakdown of the sex of subjects showed a higher percentage of females than males. This agrees with previous study where it was stated that there is a greater prevalence of female with visual disorders than male in such schools of disabilities ${ }^{8}$. It was recorded that a higher percentage of children aged 8yrs were mostly affected and children between 14-16 yrs were least affected with visual disorders. This could be attributed to possible awareness and prompt treatment in the learning environment as well as the adaptive nature of the sense organs involved.

The Pearson correlation coefficient $(-0.77)$, recorded a negative distribution such that with increasing age there was a lower percentage of visual disorders occurring in the deaf population of children. In the study group, the most common ocular/visual abnormality recorded was refractive error $(100 \%)$. Of the deaf children examined, $63(73.26 \%)$ subjects had visual disorders.

However, multiple forms of visual disorders were seen occurring in some subjects, for example, some subjects were seen to have pupillary disorders (OD), and cataract (OS), and vice versa while some others had lid abnormalities and pupillary disorders, in some other cases strabismus (OD) and pupillary disorders (OS). Ignorance of 
one or more visual disorders at birth or in early neonatal period could best explain this, thus, predisposing the child to severe forms of visual impairment. This may also arise from the presence of infections/disease in pregnant and expectant mothers such as rubella syndrome and German measles ${ }^{6}$. The overall population revealed a greater percentage of visual disorders as a result of strabismus and rubella syndrome in association with varying degrees of refractive error. The Pearson correlation coefficient findings showed a greater percentage of visual disorders in children $8 \mathrm{yrs}$ of age. This is probably due to the developing eyes of younger children who do not yet have stable refraction especially as the eyeball is still growing. These findings however showed a negative frequency distribution revealing no relationship between the pattern of age and distribution of visual disorders amongst the subjects examined.

In conclusion, the data collected showed that of the population of deaf children examined
$73.26 \%$ had visual disorders while $26.74 \%$ had no visual disorders. All the children however were observed to have significant refractive errors with a high prevalence of myopia in the population.

The Pearson correlation coefficient frequency showed a negative association between the age distribution and frequency of occurrence of visual disorder. When ocular disorders occur, prompt management should be done to reduce the individual's dependency on others as this is seen to result in very serious complications resulting in visual impairment especially in children with existing hearing loss. This endangers the life and future of this child, especially in those with a multiplicity of problems and impairments. A good education will help alleviate physical and mental isolation, improve employment opportunities as well as facilitate adequate integration of the blind and deaf as useful and productive members of the society.

\section{REF E R E N C E S}

1. Alexander, J. (1978): Ocular abnormalities among congenitally deaf children. Can. J. Ophthalmol, 39:428-33.

2. Brinks, L. (2001): Ophthalmologic screening of deaf students in Oregon. J. Pediat. Ophthalmol. Strabis, 38(1): 11-5.

3. Gilbert, C. E. and Anderson, L. (1999): Prevalence of visual impairment in children. Ophthalmic Epidemiol, 6: 73-82.

4. Coleman, H. M. (1970): An analysis of the vision of the visual status of an entire school population. J. Am. Optom. Assoc, 41:341-7.

5. Rogers, F. (1988): Screening of school-age hearing impaired children. J. Pediat. Ophthalmol, 22 (5):230-2.

6. Roizen, N. J. and Mets, M. B. (1994): Ophthalmic Disorder with Downs syndrome. Dev. Med. Child Neurol. 36: 594-600.

7. Woodruff, E. (1986): Differential effects of various causes of deafness on the eye, refractive errors, and vision of children. Am. J. Optom. Physiol. Opt. 63: 668-75.

8. Legure, L. E. and Fishman, C. (1986): A prospective study of ocular abnormalities in hearing impaired and deaf student. ENT J. 7: 64-5.

TABLE 1: SEX DISTRIBUTION OF VISUAL DISORDERS

\begin{tabular}{|l|l|l|l|l|l|}
\hline Sex & Pupil disorder & Cataract & Lid abnormality & Ocular deviations & Arcus juvenelis \\
\hline Male & 6 & 4 & 6 & 2 & 3 \\
Female & 10 & 10 & 11 & 11 & - \\
\hline
\end{tabular}

TABLE 2: SEX DISTRIBUTION OF REFRACTIVE ERRORS

\begin{tabular}{|l|l|l|l|l|}
\hline Sex & Myopia & Hyperopia & Astigmatism & Total \\
\hline Female & 22 & 8 & 12 & 42 \\
Male & 10 & 6 & 5 & 21 \\
Total & 32 & 14 & 17 & 63 \\
\hline
\end{tabular}


OSAIYUWU , A. B. AND EBEIGBE, J. A.

TABLE 3: AGE DISTRIBUTION OF CHILDREN WITH VISUAL DISORDERS WITH RESPECT TO SEX

\begin{tabular}{|l|l|l|l|r|}
\hline Age (years) & Male & \% & Female & \% \\
\hline 6 & 1 & 1.61 & 8 & 12.70 \\
7 & 2 & 3.17 & 2 & 3.17 \\
8 & 3 & 4.76 & 8 & 12.70 \\
9 & 2 & 3.17 & 4 & 6.35 \\
10 & 4 & 6.35 & 4 & 6.35 \\
11 & 2 & 3.17 & 3 & 4.76 \\
12 & 2 & 3.17 & 4 & 6.35 \\
13 & 2 & 3.17 & 4 & 6.35 \\
14 & 1 & 1.61 & 2 & 3.17 \\
15 & 2 & 3.17 & 1 & 1.61 \\
16 & - & 0.00 & 2 & 3.17 \\
\hline Total & 21 & & 42 & \\
\hline
\end{tabular}

TABLE 4: AGE DISTRIBUTION OF CHILDREN WITHOUT VISUAL DISORDERS WITH RESPECT TO SEX

\begin{tabular}{|l|l|r|l|l|}
\hline Age (years) & Male & \% & Female & \% \\
\hline 6 & 4 & 17.39 & 1 & 4.35 \\
7 & - & 0.00 & 2 & 8.70 \\
8 & 2 & 8.70 & - & 0.00 \\
9 & 3 & 13.04 & 1 & 4.35 \\
10 & - & 0.00 & 2 & 8.70 \\
11 & - & 0.00 & 1 & 4.35 \\
12 & 1 & 4.35 & - & 0.00 \\
13 & 2 & 8.70 & - & 0.00 \\
14 & 1 & 4.35 & 1 & 4.35 \\
15 & 1 & 4.35 & - & 0.00 \\
16 & 1 & 4.35 & - & 0.00 \\
\hline Total & 15 & \multicolumn{3}{l}{} \\
\hline
\end{tabular}

